\title{
Developing an Affordable and Reconfigurable Experimental Platform for Teach- ing Engineering Lab Courses
}

\section{Dr. Collins Adetu, Florida A\&M University}

Collins Adetu received his BSc in Electrical and Computer Engineering from Florida A\&M University in 2005. After graduating with his Bachelor's degree, he worked in industry before returning to Florida A\&M University to complete his MSc and Ph.D. in Electrical Engineering in 2009 and 2015, respectively. His research interests include robotic controls, teleoperation, and haptics.

\section{Dr. Camilo Ordonez, Florida State University}

Camilo Ordonez received the B.S. in Electronics Engineering from Pontificia Bolivariana University in 2003. He obtained his M.S and Ph.D. degrees in Mechanical Engineering from Florida State University in 2006 and 2010. Currently, Camilo is a Teaching Faculty at the FAMU-FSU College of Engineering. His research interests include dynamic modeling of legged and wheeled vehicles, terrain identification, motion planning, and low level control.

\section{Dr. Nikhil Gupta, Florida State University}

Nikhil Gupta received his Bachelor of Technology degree from Y.M.C.A. Institute of Technology, Haryana, India in 2008, Master of Science degree from North Dakota State University, Fargo, ND, in 2010, and $\mathrm{Ph} . \mathrm{D}$ from Florida State University, Tallahassee, FL, in 2014, all in Mechanical Engineering. He is currently an Adjunct Professor teaching Senior Design in the Department of Mechanical Engineering. He is also serving as Postdoctoral Research Associate at Center of Intelligent Systems, Control, and Robotics (CISCOR) at Florida State University. His research interests are primarily in the areas of dynamic system modeling, intelligent control, autonomous mobile wheeled and legged robotics, dynamic motion planning, and mechatronics. 


\section{Developing an Affordable and Reconfigurable Experimental Platform for Teaching Engineering Lab Courses}

Abstract

A practical understanding of theoretical engineering concepts learned in the classroom is critical to a holistic education experience. Engineering teaching labs provide an avenue for students to apply theories learned in the engineering classroom to real-world scenarios. Although teaching labs can greatly enhance the course experience, a common hindrance in developing an effective lab course is selecting an affordable experimental platform. The lab development cost can increase significantly depending on the number of lab courses and the number of seats required. Therefore, it is important to develop reconfigurable platforms for multiple courses and reduce overhead cost. In this paper, we develop an affordable and reconfigurable experimental platform, which can be used to teach topics in multiple courses. The proposed platform can be reconfigured to administer topics in mechatronics, controls, computer programming, and robotics. For our design, most of the platform is made from plywood that is laser cut for low cost rapid fabrication. The National Instrument (NI) myRIO embedded device is used to interact with actuators and sensors. Programming of the NI myRIO is accomplished using the NI LabView software. To connect different sensors to the NI myRIO embedded device we design a breakout board making it easier to interface with the embedded device. Sample experiments in controls and robotics are provided in the paper to highlight how the platform could be used to teach topics in multiple courses. Due to the affordable and reconfigurable design, this platform can also be used to teach science, technology, engineering and math (STEM) concepts at various levels of education. Developing a low-cost yet effective experimental platform that can be leveraged for use in multiple topics encourages students to become critical thinkers while employing the skills learned in the classroom.

\section{Introduction}

In recent years there is a rapid growth in the demand of multidisciplinary education and research, especially in the field of robotics ${ }^{1-3}$. The shift is mainly due to the need of retaining competitive edge in innovation through STEM education and research for the 21st century. Multidisciplinary education proves to be helpful in revitalizing STEM education that can provide hands-on research experience to the students. Mechatronics, Robotics, Embedded Systems, and Controls can be used as important tools for multidisciplinary education and research.

A practical understanding of theoretical engineering concepts learned in the classroom, such as mechatronics and robotics, is critical to a holistic education experience. Engineering teaching labs, especially of multidisciplinary expect, provide an avenue for students to apply theories learned in the engineering classroom to real-world scenarios. Although multidisciplinary teaching labs can greatly enhance the course experience, a common hindrance in developing an effective lab course is selecting an affordable experimental platform. The lab development cost can increase significantly depending on the number of lab courses and the number of seats 
required $^{4,5}$. Therefore, it is important to develop reconfigurable platforms for multiple courses and reduce overhead cost. In this paper, we present the development of an affordable and reconfigurable experimental platform, which can be used to teach topics in multiple courses at various levels such as, robotics at the high school level, Introduction to Mobile Robotics and Design and Analysis of Controls Systems at the university level.

The remainder of the paper is organized as follows. Section II provides details on the platform design and configuration options. In Section III we present case studies showing the platform being used to teach a high school level robotics workshop, an undergraduate and graduate level Design and Analysis of Control Systems course, and an undergraduate and graduate level Introduction to Mobile Robotics course. In Section IV we present post survey results collected from the students and discuss potential improvements to be implemented in subsequent versions of the platform. Finally, we present concluding remarks in Section V.

\section{Platform Design}

In an effort to create a low-cost experimental platform that could be used for multiple engineering courses, we decided to use recycled 0.25 inch plywood to create a reconfigurable base chassis. The base chassis was designed by a team of 4 members including, 2 students (1 undergraduate and $1 \mathrm{Ph}$.D. student), 1 research associate, and 1 teaching faculty.

As part of the design constraints the platform was expected to be used in multiple engineering courses, therefore the platform had to be reconfigurable. Also in order to keep the platform portable the weight was kept under $3 \mathrm{lbs}$ and its dimensions had to be under 20" x 15" x 10" (L x $\mathrm{W} \times \mathrm{H})$. To meet these constraints, the base chassis was built using two flat pieces of plywood that would serve as the top and bottom platform of the chassis. In order to house the battery, a compartment was created in between the top and bottom plywood platforms. To create the battery compartment, puzzle-like plywood pieces were designed with ridges which were inserted into holes on the top and bottom platforms. Additional holes were cut into the top and bottom platforms for motor mounts and sensors. After multiple design iterations, the final design was cut out from plywood pieces using a laser cutter available in the lab. The upper and lower plywood platforms were supported by four 2 inch long wooden dowels and the puzzle-like pieces used to create the battery compartment. Figure 1 shows all the components used to build the experimental platform including the wooden parts used for the chassis. A list of all the components used to build the experimental platform and their unit prices are provided in Table 1.

To support embedded programming of the experimental platform, we decided to integrate National Instrument's myRIO. The NI myRIO provides a scalable platform that could be used for multiple engineering courses. NI myRIO with its onboard devices, seamless software experience, and library of courseware and tutorials provides an affordable tool that students can use to learn important engineering concepts and develop real engineering projects. NI myRIO comes with a dual-core $\mathrm{ARM}^{\circledR} \mathrm{Cortex}^{\mathrm{TM}}$-A9 real-time processor and a $667 \mathrm{MHz}$ Xilinx FPGA for customizable I/O. Figure 2 shows the embedded architecture of NI myRIO and its specifications are as follows:

- Xilinx Zynq System on a Chip 
- Analog Input (10 Channels)

- Analog Output (6 Channels)

- Analog Input and Output also available through $3.5 \mathrm{~mm}$ Audio Jack

- 40 Digital I/O Lines

- Wireless Enabled

- Accelerometer, LEDs, and Push Button Onboard

- $6 \mathrm{~V}$ to $16 \mathrm{~V}, 14 \mathrm{~W}$ Power Requirement

- Powered by NI LabView

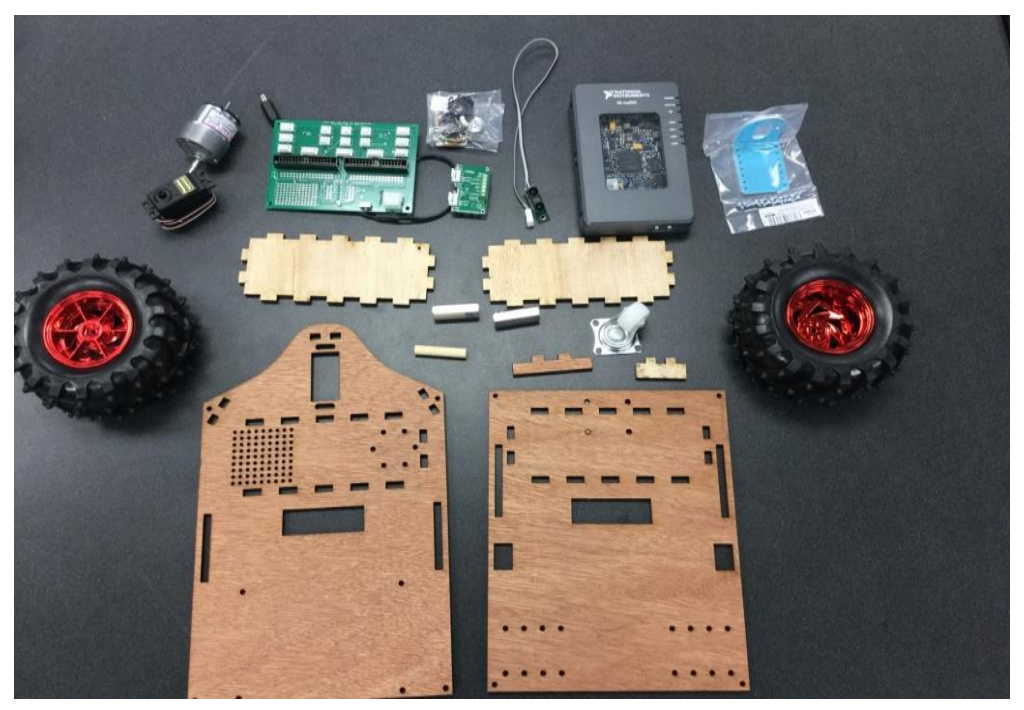

Figure 1: Components required for building the experimental platform.

Table 1. Bill of Materials

\begin{tabular}{|c|c|c|c|}
\hline Category & Parts & Description & Cost \\
\hline \multirow[t]{3}{*}{ Chassis } & Wood & $\begin{array}{l}\text { Plywood } 0.25 " \times 18 \text { " x } 15 \text { " } \\
\text { Dowels } 0.25 \text { " x 2" }\end{array}$ & $\$ 3.00$ \\
\hline & Spacers & Plastic 5/16" OD x 1.5 " & $\$ 0.85$ \\
\hline & Wood screws & Size $20.5 ”$ & $\$ 0.50$ \\
\hline \multirow[t]{4}{*}{ Drive System } & Caster wheel & $1 " \times 0.5 "$ & $\$ 2.00$ \\
\hline & Active wheel & $2 \times 120 \mathrm{~mm} \times 60 \mathrm{~mm}$ & $\$ 14.95$ \\
\hline & DC motor & 7.2V 175 rpm 99.04 oz-in & $\$ 21.95$ \\
\hline & Servo motor & Futuba S3003 & $\$ 12.09$ \\
\hline
\end{tabular}




\begin{tabular}{|c|c|c|c|}
\hline \multirow[t]{5}{*}{ Sensors } & Encoder & $\begin{array}{l}\text { Quadrature Motor Encoder } 400 \text { counts per } \\
\text { revolution }\end{array}$ & $\$ 30.95$ \\
\hline & IR sensor & Sharp 4"- 60" range & $\$ 11.95$ \\
\hline & Current sensor & $\begin{array}{c}\text { Allegro's } \pm 75 \text { A ACS709 Hall effect- } \\
\text { based }\end{array}$ & $\$ 9.95$ \\
\hline & Motor brackets & $\begin{array}{l}\text { Aluminum L-bracket pair for 37D mm } \\
\text { metal gear motors }\end{array}$ & $\$ 7.95$ \\
\hline & Motor driver & Dual motor driver 5-28V $3 \mathrm{~A}$ & $\$ 29.95$ \\
\hline \multirow[t]{3}{*}{$\begin{array}{l}\text { Breakout } \\
\text { Board }\end{array}$} & $\begin{array}{l}\text { Voltage } \\
\text { regulator }\end{array}$ & $5 \mathrm{~V}, 2.5 \mathrm{~A}$ step-down regulator & $\$ 10.95$ \\
\hline & $\begin{array}{l}\text { PCB with } \\
\text { connectors }\end{array}$ & $\begin{array}{l}\text { Printed circuit board with special } \\
\text { connectors }\end{array}$ & $\$ 12.00$ \\
\hline & $\begin{array}{l}\text { Battery with } \\
\text { Charger }\end{array}$ & 2 x 7.2V 3800mAh NiMH & $\$ 59.00$ \\
\hline $\begin{array}{l}\text { Embedded } \\
\text { Device }\end{array}$ & NI myRIO & Xilinx Z-7010 Dual Core $667 \mathrm{MHz}$ & $\$ 500.00$ \\
\hline
\end{tabular}




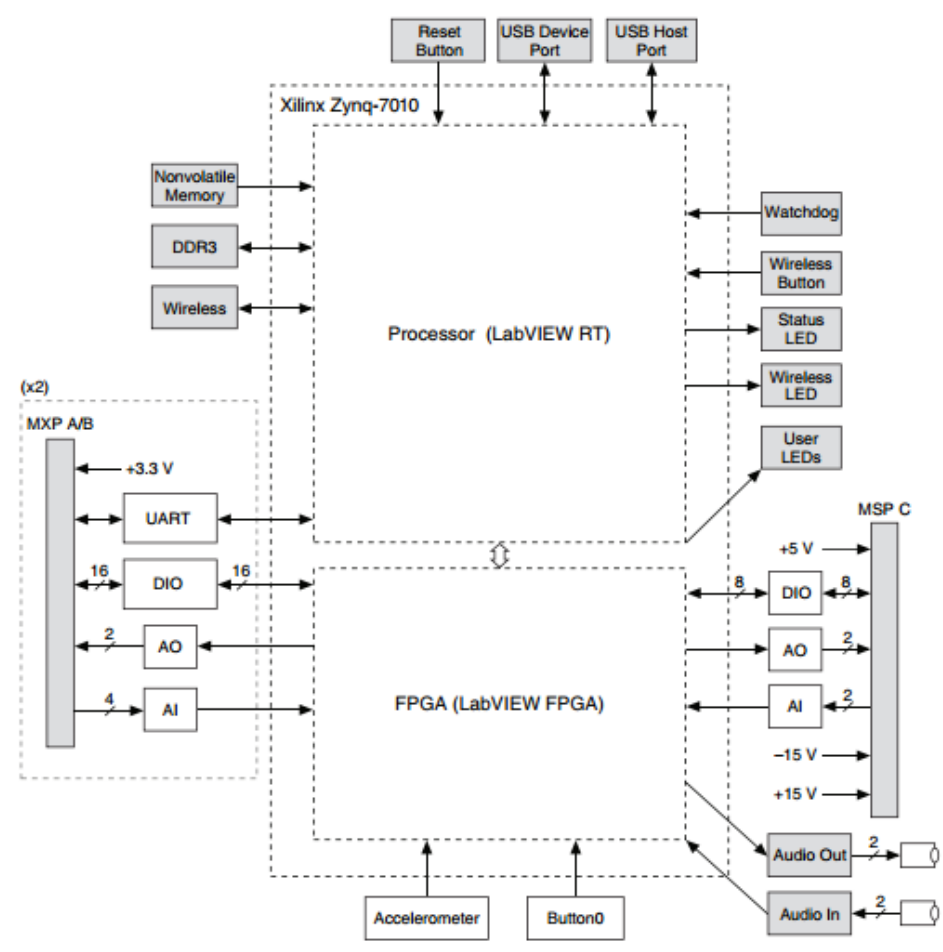

Figure 2: Embedded architecture of NI myRIO $1900^{6}$.

In order to interface with the NI myRIO we created an electronic breakout board. The breakout board consists of a $5 \mathrm{~V}$ voltage regulator, four 34-pin connectors, two 10-pin connectors, six 3pin digital input/output connectors, six 4-pin analog connectors, a 5-pin UART connector, a 5pin SPI connector, and a 5-pin I2C. It also has a switch and power connector for the battery. The 34-pin connector on the breakout board can be connected directly to the 34-pin connectors on the myRIO using a ribbon cable. This is to access myRIO pins without running individual jumper wires directly to each pin. Figure 3, shows the breakout board and the 34-pin connectors on the NI myRIO. To power the experimental platform, one battery is used for the motors while the other battery is used to power the breakout board and the myRIO. A 5V, 2.5 step down regulator is added to the breakout board to provide on-board power for all sensors connected to the board. 


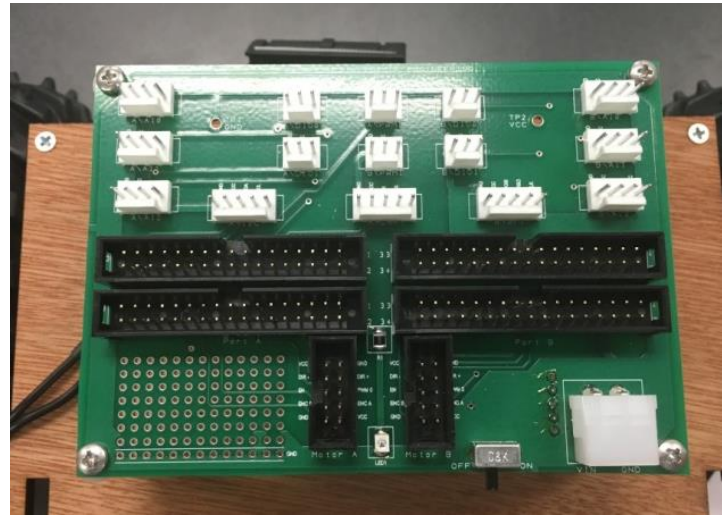

(a)

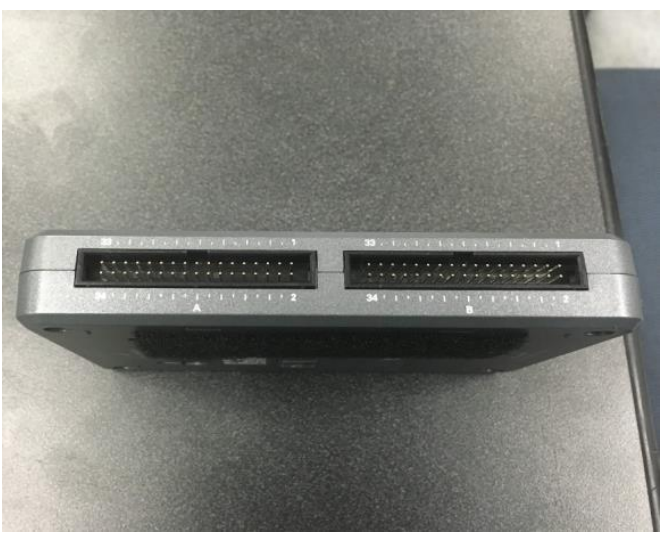

(b)

Figure 3: (a) PCB breakout board, (b) 34-pin connectors on NI myRIO.

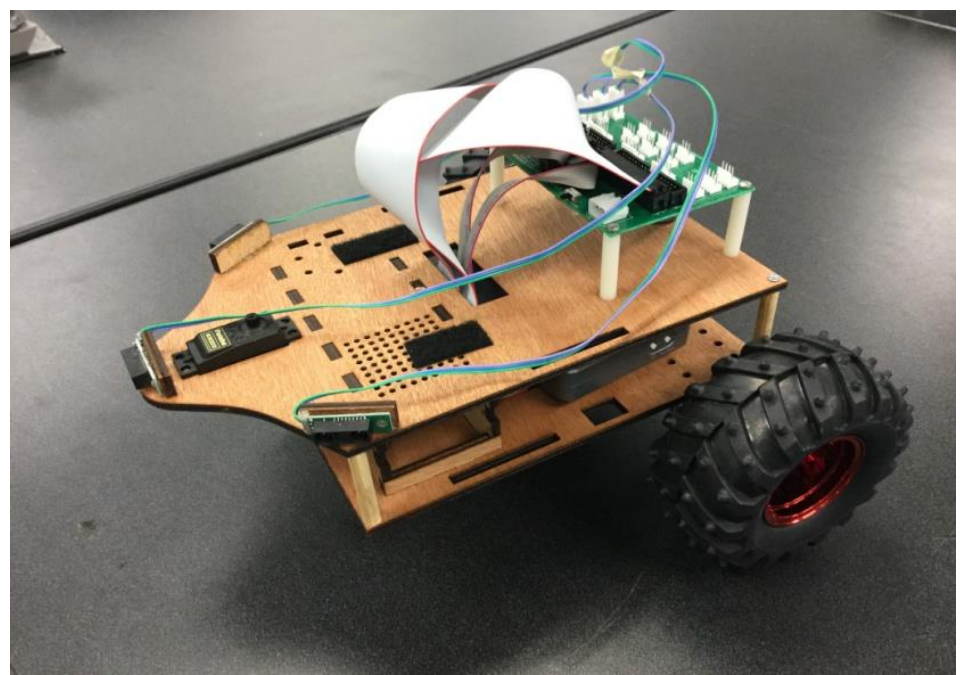

Figure 4: Mobile robot base configuration used in Section III Case Study 1 and 3.

As mentioned earlier, one of the objectives for designing this platform is to provide a reconfigurable experimental platform for teaching multiple courses. To emphasize this characteristic, we present two different configurations of the base chassis: the mobile base configuration and the controls system configuration. Both configurations were employed in the case studies described in Section III of the paper.

Figure 4 shows the mobile base configuration which consists of two DC motors, a pair of monster truck-style wheels, a caster wheel, two 7.2 V 3800mAh batteries, a dual motor driver, three IR sensors, and a servomotor. Since most of the platform is made from wood, most of the assembly requires only a screwdriver and wood screws. The DC motors are mounted to the bottom of the platform using aluminum L-brackets. A pair of monster truck-style wheels are connected to the motor shafts and a caster wheel is mounted to the front of the bottom platform. 
A dual motor driver is mounted to the bottom platform to control the DC motors. The NI myRIO is placed in between the top and bottom platforms and attached using Velcro. The dimensions for the mobile robot platform is 12 inches $x 10$ inches $x 8$ inches.

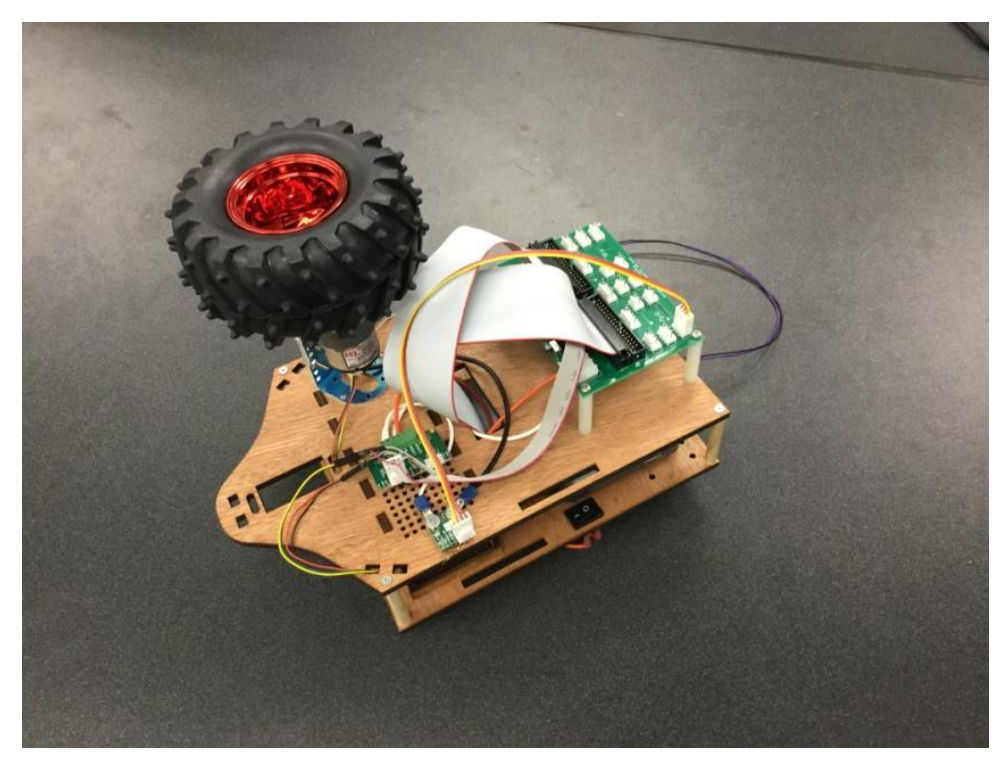

Figure 5: Single wheel setup employed in case study 2

For the controls system configuration only one DC motor and wheel is required, with the wheel mounted on the top platform of the chassis as shown in Figure 5. For this configuration, a current sensor is added in series with the motor. With the exception of the IR sensors, which are removed, all the other components remain the same as those used on the mobile platform configuration.

\section{Case Studies}

We present a few case studies in which the experimental platform was used to teach engineering concepts to students in both the high school and college level. We first describe the platform being configured as a mobile robotic base to teach STEM concepts to high school students. In addition, the platform is reconfigured to teach dual-enrolled undergraduate and graduate Design and Analysis of Control Systems course. Finally, we show the platform being used as a mobile robotic base to teach a dual-enrolled undergraduate and graduate Introduction to Mobile Robotics course.

\section{A. High School STEM Workshop}

In order to teach certain STEM concepts, the platform was configured as a mobile robotics base as shown in Figure 4. The main objectives of the workshop were:

- Familiarize the students with various sensors used with mobile robots. 
- Familiarize the students with programing concepts using a graphical program tool like NI LabView.

- Teach STEM concepts by converting IR sensor readings to distances.

We had 12 students ranging from the 10th to the 12th grade participate in the workshop. The workshop lasted for four hours. The first two hours were spent teaching the students about various components of the mobile robot, which included the infrared sensors, wheel encoders, motor drivers, and the National Instrument (NI) myRIO embedded device. During this period the students were also exposed to the programming fundamentals using NI LabView to interact with the NI myRIO.

For the next phase of the workshop, the students were broken up into teams and expected to assemble the robot and characterize the infrared sensor. Instructions were given to each team on how to assemble the robot. Using only a Philips screwdriver and an Allen key the students were able to assemble the robot. To characterize the infrared sensor, the students had to set up objects at known marked distances away from the infrared sensor while recording the corresponding voltage readings. The students programmed the mobile robot to collect one hundred readings at each of the following marked distance from the sensor: 10, 20, 30, 40 and $50 \mathrm{~cm}$. The students computed the average of the 100 readings for each marked distance and plotted the distance versus voltage data. Using a best fit curve, they were able to determine an equation that described an object's distance from the infrared sensor based on the voltage reading from the sensor. In order to successfully complete the workshop, the students had to use several STEM concepts. One of such STEM concepts included an understanding on how the infrared sensors worked. They also had to employ math concepts in order to determine the equation that related the sensor voltage to the object distance.

To conclude the workshop, we had the students complete an anonymous post survey. As part of the post survey, we inquired about the student's experience with the platform. The survey and results are discussed in Section IV of this paper.
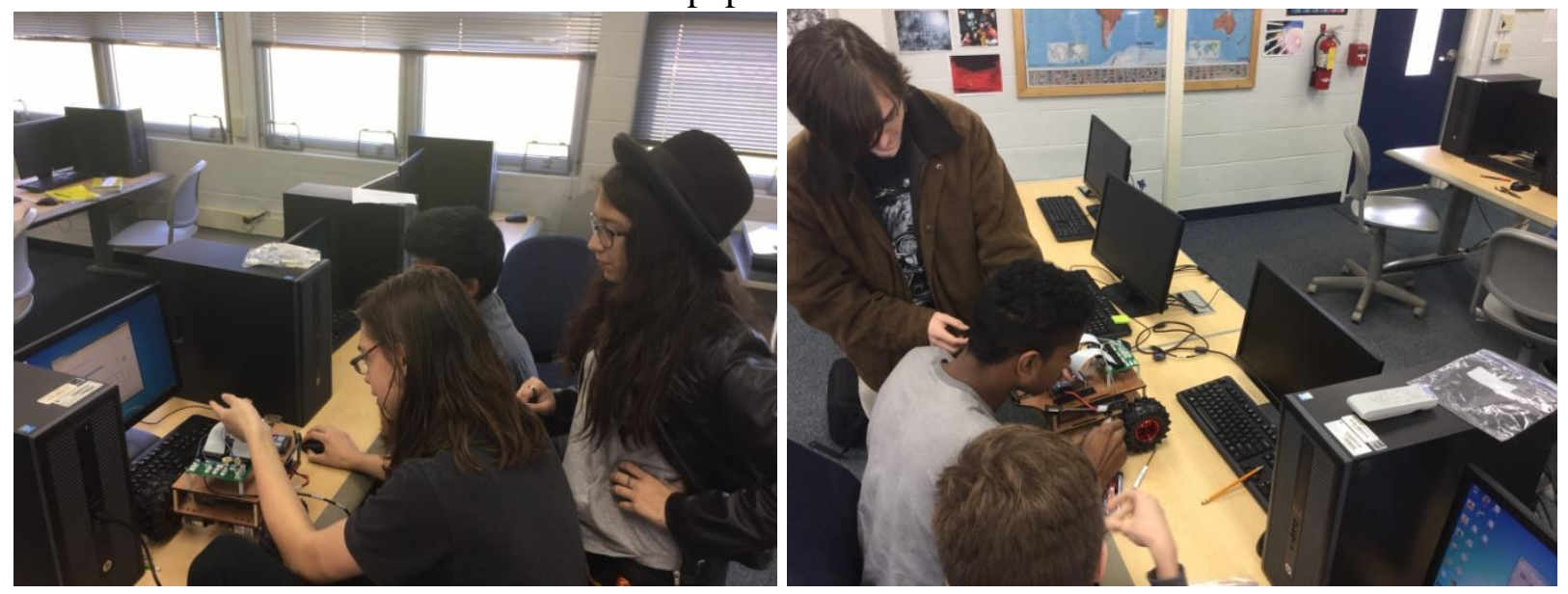

Figure 6: Robotics workshop held with local high school students 


\section{B. Design and Analysis of Control Systems}

In order to target a different type of students a controls systems was selected. This class is taken by both senior undergraduate and first year graduate students at the department of Mechanical Engineering. While in the past, other groups ${ }^{7}$ have used alternative platforms like the LEGO Mindstorms to teach control labs, it was determined that the Lego platforms do not offer the same mechanical robustness and flexibility of the platform proposed here.

For this particular class, we make use of the reconfigurable capabilities of the platform. As shown in Figure 5, a single wheel is mounted on the top plate of the platform. In addition, a current sensor is added to monitor the current flowing through the motor.

The main objectives of the lab were:

- Familiarize the students with software and hardware commonly used in control applications.

- Develop the necessary skills to perform system identification of a linear single input single output system.

- Design and implement position and velocity control laws for the single wheel setup.

With these objective in mind, three laboratory experiments were developed and conducted. In the first lab, the students are asked to assemble and make all the electrical connections of the platform. By doing this, they get familiarized with components such as optical encoders, current sensors, and motor controllers, which are frequently used in control applications. As part of the first lab, the students also got an introduction to LabVIEW and the myRIO platform.

In the Second lab, students applied system identification techniques to identify a transfer function (relating velocity to voltage) of the single wheel setup. While in the third lab, the students developed and implemented position and velocity controllers for the platform. This lab reinforced the concepts learned in class in the topics such as root locus, PD, and PI compensators.

At the end of the class a 17-question survey was conducted to study the student perception on the platform as a lab teaching tool. The survey questions and the obtained data are summarized in Annexure I.

\section{Introduction to Mobile Robotics}

The Introduction to Mobile Robotics course is a dual-enrolled undergraduate and graduate level course. It serves as an elective course and available to junior and senior level undergraduate students that have completed a prerequisite course in mechatronics or a programming course. A crucial part of the course objective is to provide the students hands-on experience in programming a mobile robot. As part of the course outcomes, the main objectives of the lab include:

- Familiarize the students with various sensors used with mobile robots.

- Develop kinematic models and controllers for mobile robots. 
- Develop motion planning and obstacle avoidance algorithms for mobile robots.

To meet these objectives the lab was broken into four lab exercises. For the first lab, the students were required to assemble the robot and wire all motors and sensor. The students were divided into groups of three and given all the individual parts and tools needed to assemble the mobile robot. The lab session provided an opportunity for the students to become familiar with the various components of the mobile robot. The students were also given the opportunity to solder connectors on the electronic breakout board that interfaced with the NI myRIO.

For the second lab session, the students developed a kinematic model and controller for the mobile robot. The mobile robot was modelled as a differential steered mobile robot since it consisted of two active wheels and a caster wheel at the front. Measurements of wheels radii and distance between the active wheels were taken by the students in order to develop the model. The kinematic model and a PD controller for the robot developed by the students using NI LabView. To validate the model and PD controller, the students commanded the robot at different velocity and logged position data obtained from the motor encoders. The velocity of the mobile robot was also logged by differentiating the wheel position values.

The objective for third lab session was to develop obstacle avoidance and path planning strategy for the mobile robot using the potential field algorithm. The students retrofitted the mobile robot with IR sensors and derived empirically an equation relating sensor voltage to distance. The students developed a potential field algorithm to navigate from a start position to a goal position while meandering through obstacles. Figure 7(a) shows the robot after reaching its goal, while Figure 7(b) shows the trajectory of the robot from the data logged from the wheel encoder.

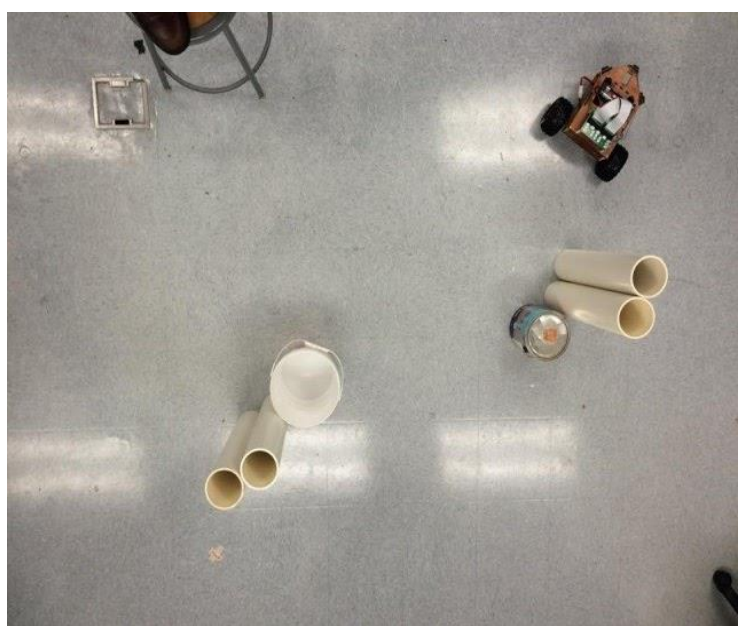

(a)

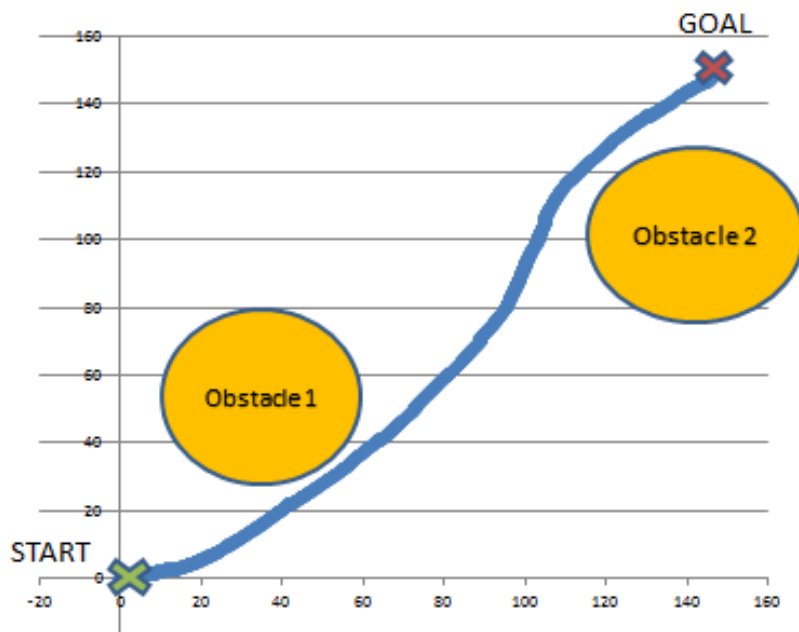

(b)

Figure 7: (a) Obstacle avoidance and path planning experimental setup, (b) robot trajectory while navigating obstacles. 
The final lab focused on the concept of Kalman filters. The students were required to use a Kalman filter to track the position of another robot moving at constant velocity. This experiment required two robots, one labelled as the "prey" and the other labelled as the "predator". Using the IR sensor, the predator robot should be able to track the prey robot. In addition, the predator should be capable of predicting the position of the prey when its IR sensor is occluded. The students developed a Kalman filter in NI LabView to track the position of the prey robot.

At the end of the semester, the students were presented with a survey asking various questions including their experience with the platforms. The feedback obtained from the students are discussed and analyzed in Section IV of this paper.

\section{Lessons Learned and Challenges Faced}

To ensure that the platform was effective, we provided the students with surveys to get some feedback on their experience with the experimental platform. Common to all three case studies, we included 4 questions specific to the students experience with the platform. A total of 36 high school and college level students were surveyed. Out of the 36 students, 12 were high school students that participated in the robotics workshop, 15 were college students enrolled in the Design and Analysis of Controls Systems course, and 9 were college students enrolled in the Introduction to Mobile Robotics course.

The first question focused on the assembly of the platform. The students were asked to select a choice that best describes their experience with assembling the platform from the following options: very easy, easy, neutral, difficult, and very difficult. Figure 8 shows the response gathered from the students with regards to the ease of assembly. Of all the students surveyed most of them suggested that the assembly of the experimental platform was either easy or very easy. 11 students were neutral and 4 students considered the assembly either difficult or very difficult.

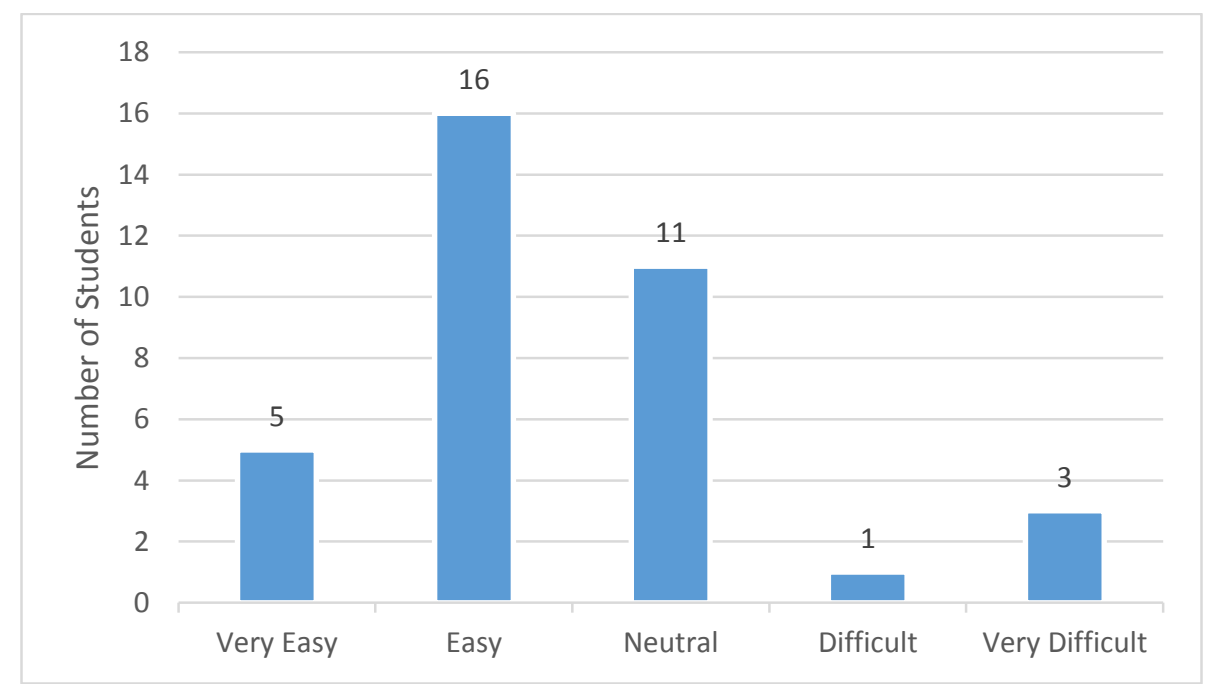

Figure 8: Results to the survey question, "Select a choice that best describes your experience with assembling the platform" 
The second question surveyed the student's opinion on the modularity of the platform. The students were asked to choose if they strongly agreed, agreed, felt neutral, disagree, or strongly disagree with statement: the platform provided a modular design which allowed sensors and parts to be easily added and replaced.

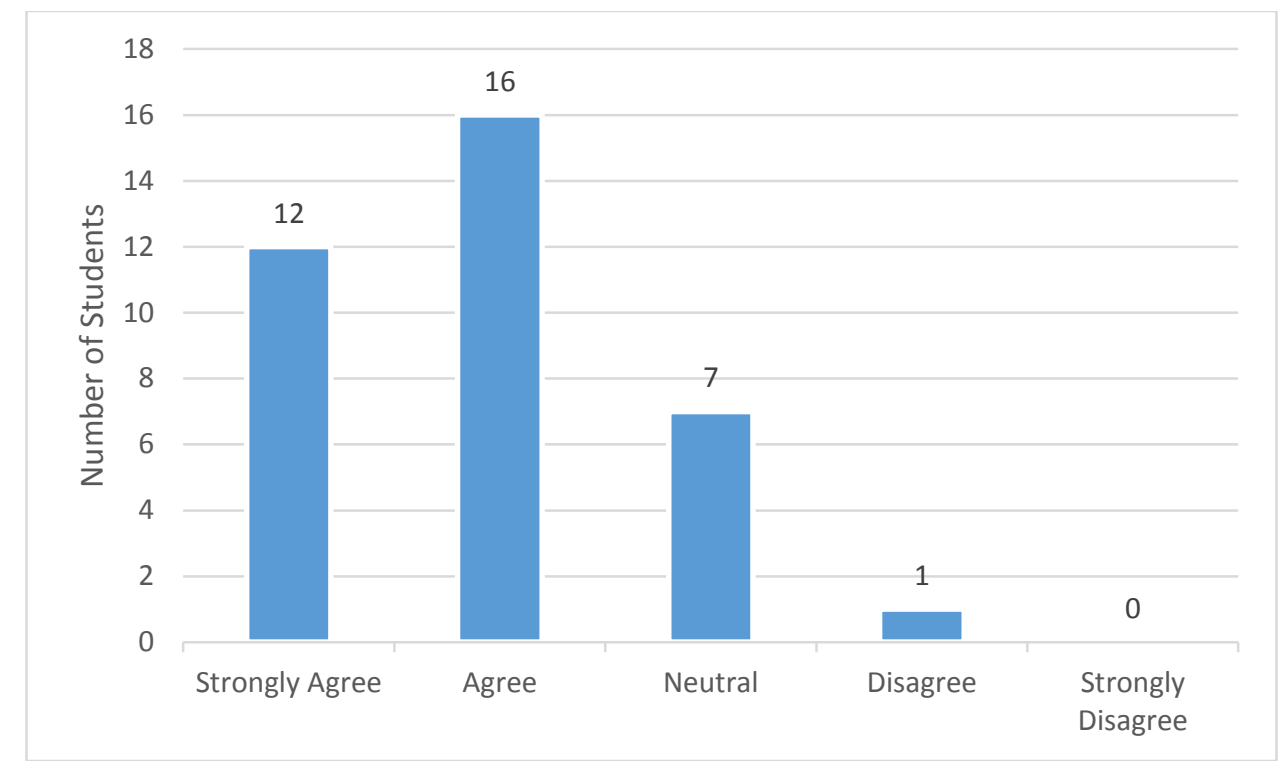

Figure 9: Response to the statement: "The platform provided a modular design which allowed sensors and parts to be easily added or replaced"

Figure 9, presents the response regarding the modularity of the platform. Almost all the students believed the platform provided a modular design. The fact that the platform was made out of wood made easy for sensors to be easily mounted.

The third question focused on capability of the platform being used for other courses. The students were asked if they will recommend using the platform for other lab courses. Most of the students agreed they would like to see this platform used for other labs as shown in Figure 10. Some of the students suggested using the platform for a mechatronics course. This platform could also be used in teaching other mobile robotics courses ${ }^{8}$, including even FPGA courses ${ }^{9,10}$ due to the FPGA capability of the myRIO. 


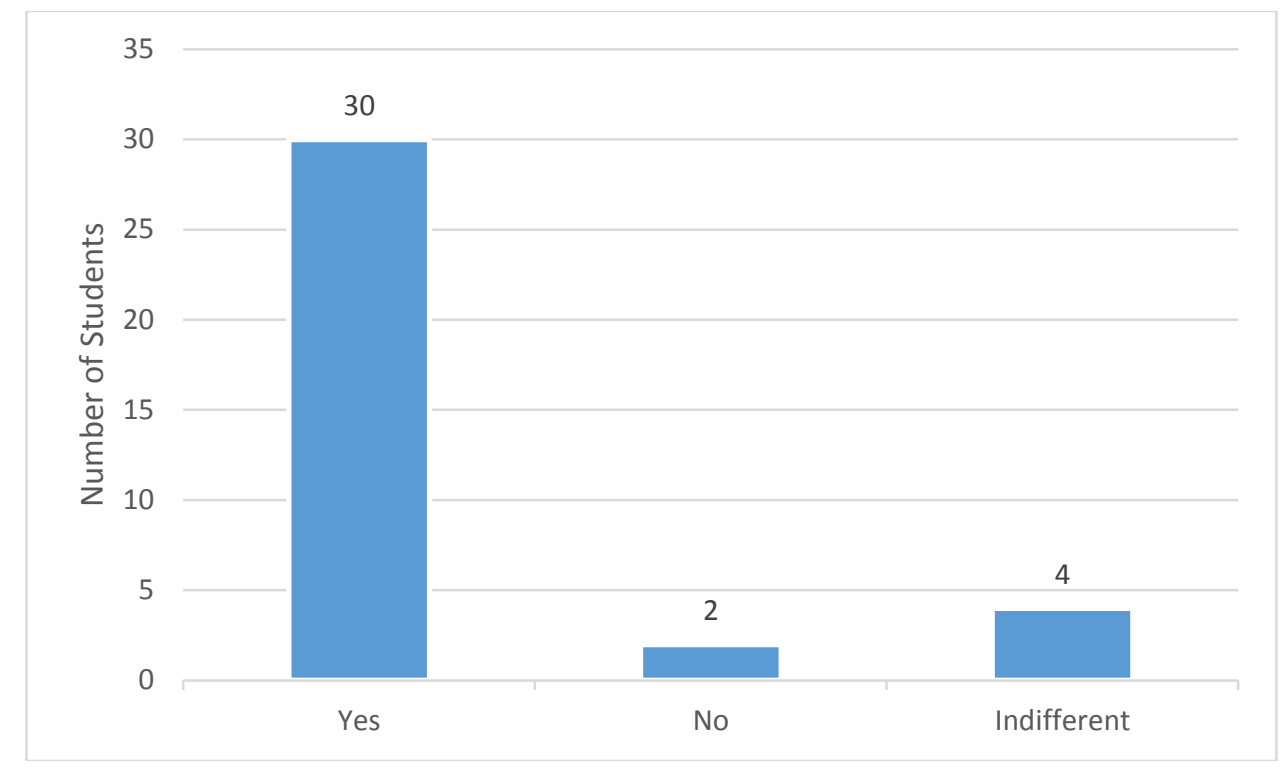

Figure 10: Response to the question: "Would you recommend using this platform for other lab courses?"

We also asked the students for suggestions on improving the platform, below are a few of the responses provided by the students:

- "Consider adding a camera to provide the robot with computer vision"

- "Make the IR sensor mounts fit tighter to the holes on the top platform of the robot"

- "Provide more spacing for the switch on the bottom platform"

- "Make the USB port of the NI myRIO more accessible, it is difficult to connect the USB cable because the port is too close to the wheel"

In addition to the suggestions proposed by the students, we also noticed that the caster wheel took some time to assemble due to the difficulty in accessing the mounting screws which were directly under the battery compartment. Also, the ribbon cables block access to the switch on the breakout board. We plan on moving the position of the switch in future iteration. Finally, to hold the NI myRIO in place, we used Velcro. This made it difficult to remove the myRIO because there was very little room between the top and bottom platform. We will consider creating grooves in the next implementation of the platform so that students can easily slide and lock the myRIO in place.

\section{Conclusion and Future Work}

In this paper we set out to develop an affordable and reconfigurable platform that could be used to teach multiple engineering courses and STEM concepts to pre-collegiate students. The platform we created was built mostly from plywood. The cost of the platform and all the components purchased with the exception of the embedded NI myRIO device came up to $\$ 302$. This platform could be used with other embedded devices like the Arduino which could be a cheaper alternative to the NI myRIO. The versatility of this platform to be used in various engineering courses also provides a major cost savings in the long term. We presented three 
different cases where the platform was used to teach engineering courses and STEM concepts at various education levels. The feedback obtained from the surveys will be used to improve future iterations of the platform. Also, we plan on using other embedded device platforms like the Arduino for future renditions.

\section{References}

1. Maja J. Mataric, "Robotics Education for All Ages", Proceedings, AAAI Spring Symposium on Accessible, Hands-on AI and Robotics Education, Palo Alto, CA, Mar 22-24, 2004.

2. Alimisis, D., Karatrantou, A., Tachos, N. "Technical school students design and develop robotic gear-based constructions for the transmission of motion”, In Gregorczyk G., WalatA., Borowiecki M., (eds.), Eurologo 2005, Digital Tools for Lifelong Learning, Proceedings, Warsaw: DrukSfera, pp. 76-86

3. Johnson, Jeffrey "Children, robotics, and education", Artificial Life and Robotics, vol. 7, no.1, 2003, pp. 16-21.

4. Feisel, Lyle D., and Albert J. Rosa. "The role of the laboratory in undergraduate engineering education." Journal of Engineering Education, vol. 94, no. 1, 2005, pp 121-130.

5. Weitzen, Jay; Webster, Erin; and Alan Rux. "University of Massachusetts Lowell "Laboratory in a Box" For First Year ECE Students." Proceedings American Society of Engineering Education, 2013.

6. "User guide and specification NI myRIO-1900." http://www.ni.com/pdf/manuals/376047a.pdf

7. Mosteo, A.R.; Tardioli, D.; Montijano, E., "The LEGO Pardo Experience: Motivational Control Demonstrations for Cadets [Focus on Education]," in IEEE Transactions on Control Systems, vol.34, no.6, pp.78-126, Dec. 2014.

8. Alisa Gilmore, P. E. "Design Elements of a Mobile Robotics Course Based on Student Feedback." American Society of Engineering Education, 2015.

9. Liu, Cheng Chih. "Teaching Digital Designs by Building Small Autonomous Robotic Vehicles Using an FPGA Platform." American Society of Engineering Education, 2015.

10. Akash Kumar, et al., "Project-Based Learning in Embedded Systems Education Using an FPGA Platform," IEEE Transactions on Education, Vol. 56, no. 4, August 2013 


\section{Annex I (Questionnaire Case Study II)}

Q1. How would you rate your skills in experimental estimation of transfer functions before taking this lab?

Q2. How would you rate your skills in experimental estimation of transfer functions after taking this lab?

Q3. How would you rate your understanding and competency in implementing P, PI, and PD control laws before taking this lab?

Q4. How would you rate your understanding and competency in implementing P, PI, and PD control laws after taking this lab?
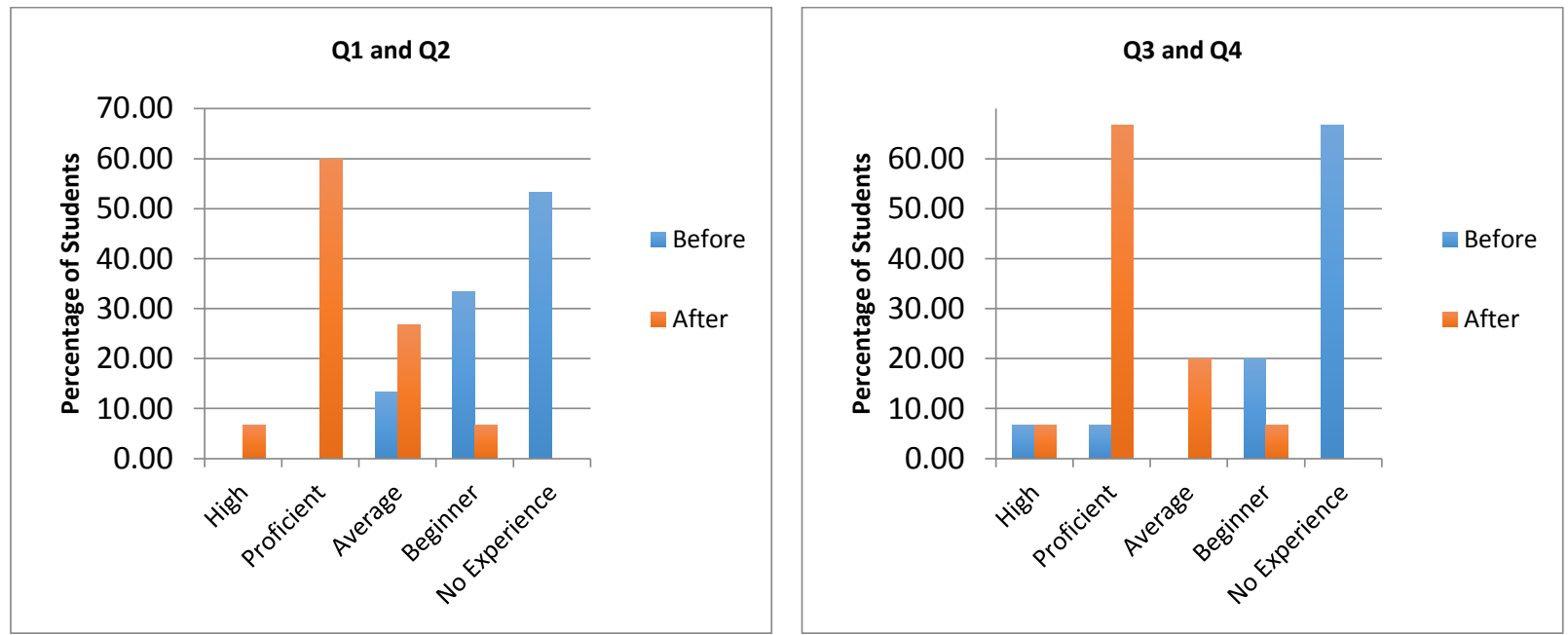

Q5. How would you rate your competency in utilizing root locus to design control laws before taking this lab?

Q6. How would you rate your competency in utilizing root locus to design control laws after taking this lab?

Q7. How would you rate your competency in utilizing computational tools such as Matlab and Simulink to analyze and design control systems before taking this lab?

Q8. How would you rate your competency in utilizing computational tools such as Matlab and Simulink to analyze and design control systems after taking this lab? 


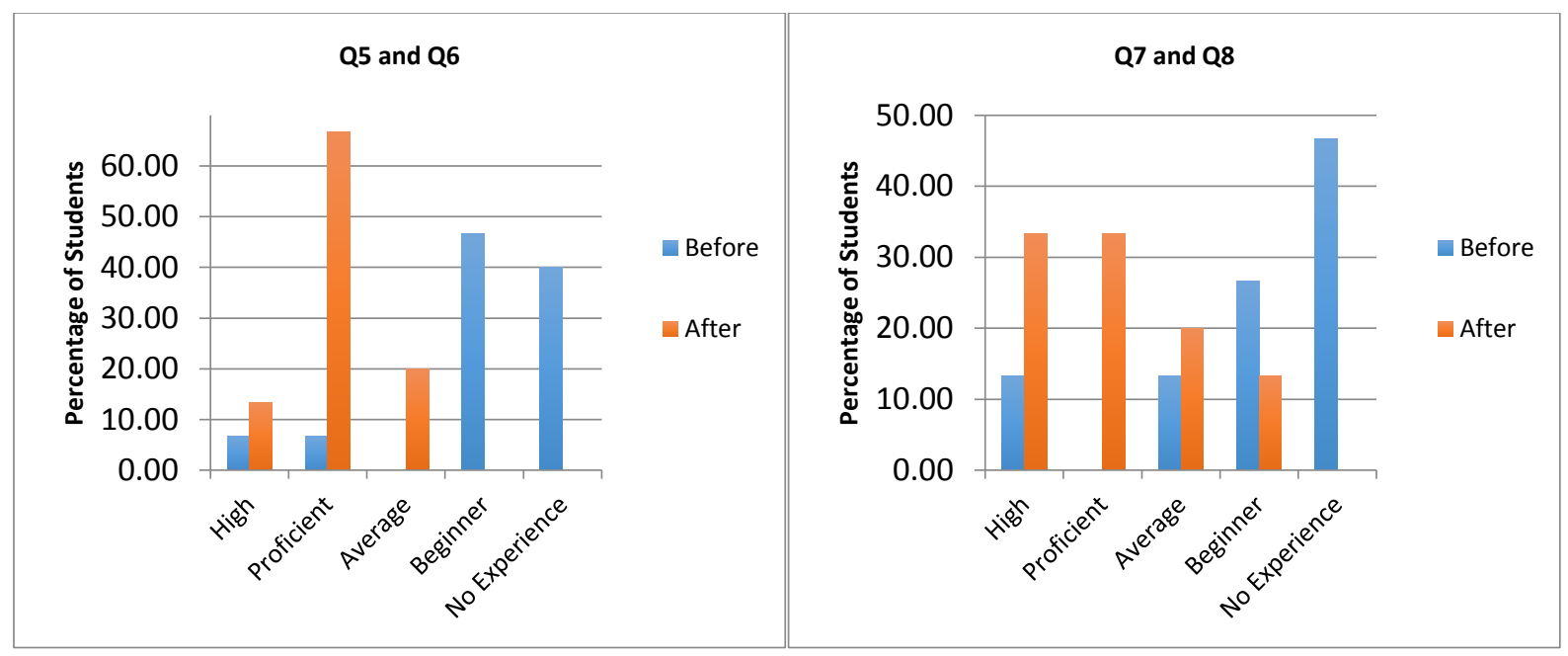

Q9. Select one choice that describes the assembly of the platform used for the lab.

Q10. The platform provided a modular design that allowed sensors and parts to be easily added or replaced.
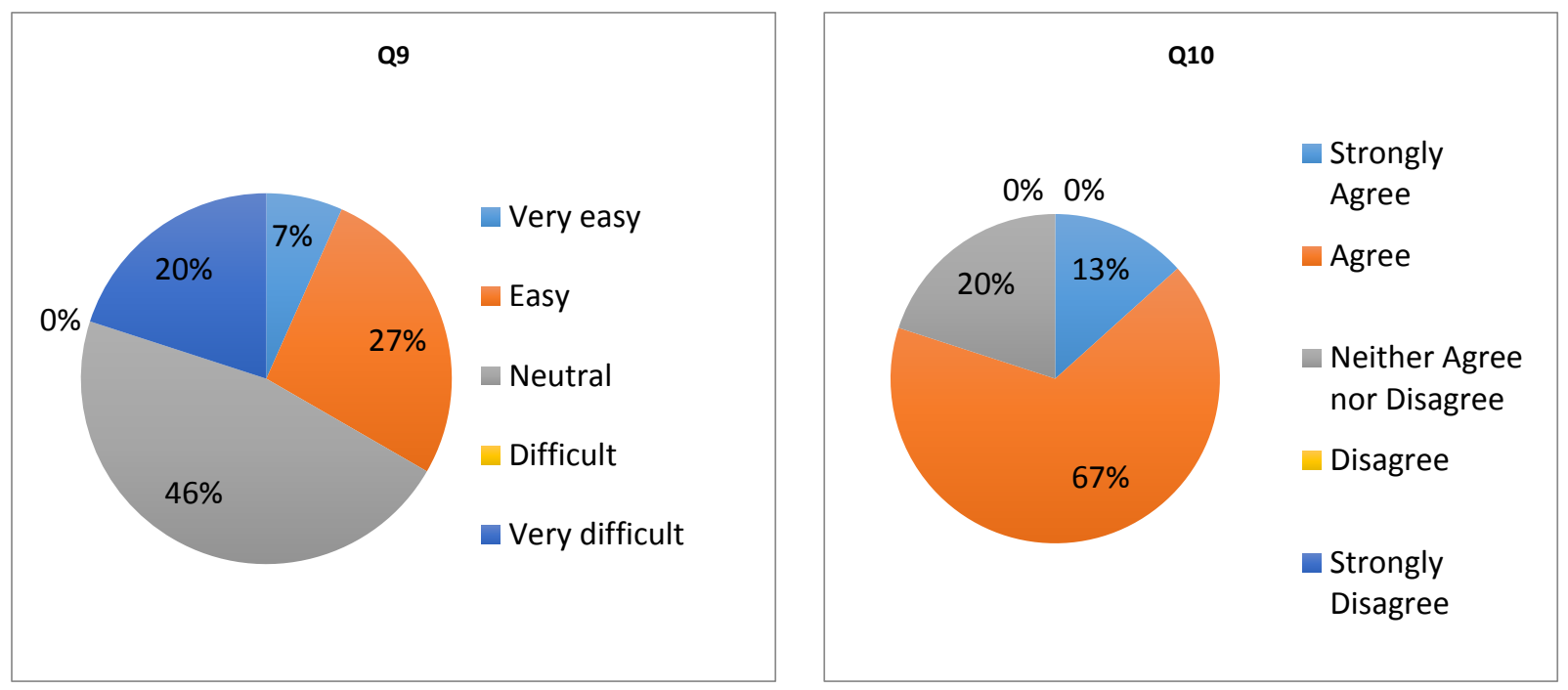

Q. 11. How would you rate your understanding of the interaction of components such as encoders, DC motors, analog to digital converters, PWM signals, and current sensors within a control system before taking this lab?

Q.12 How would you rate your understanding of the interaction of components such as encoders, DC motors, analog to digital converters, PWM signals, and current sensors within a control system after taking this lab? 
Q. 13 How would you rate your competency in LabVIEW prior to taking this lab?

Q. 14 How would you rate your competency in LabVIEW after taking this lab?
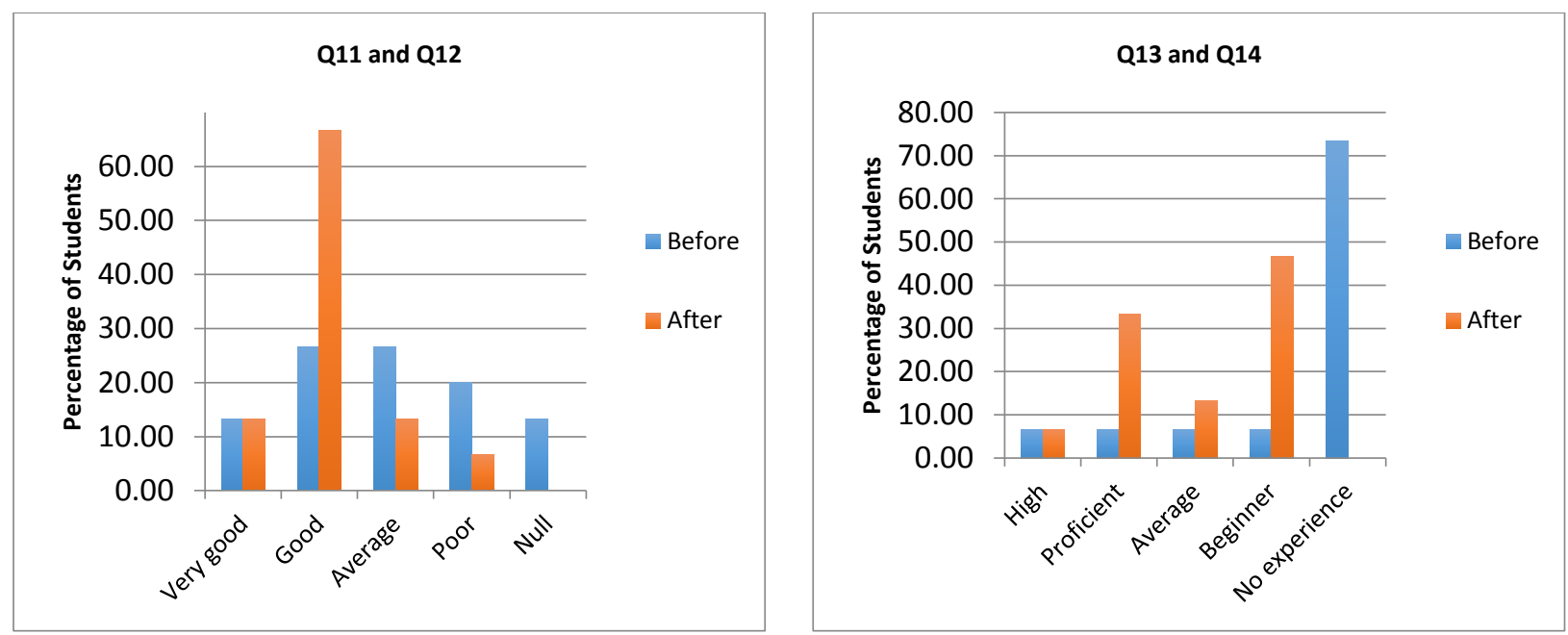

Q.15 Would you recommend using this platform for other lab courses?

Q. 16 Do you feel that this lab increased your confidence implementing control systems and will help you retaining and applying the learned techniques in the future?

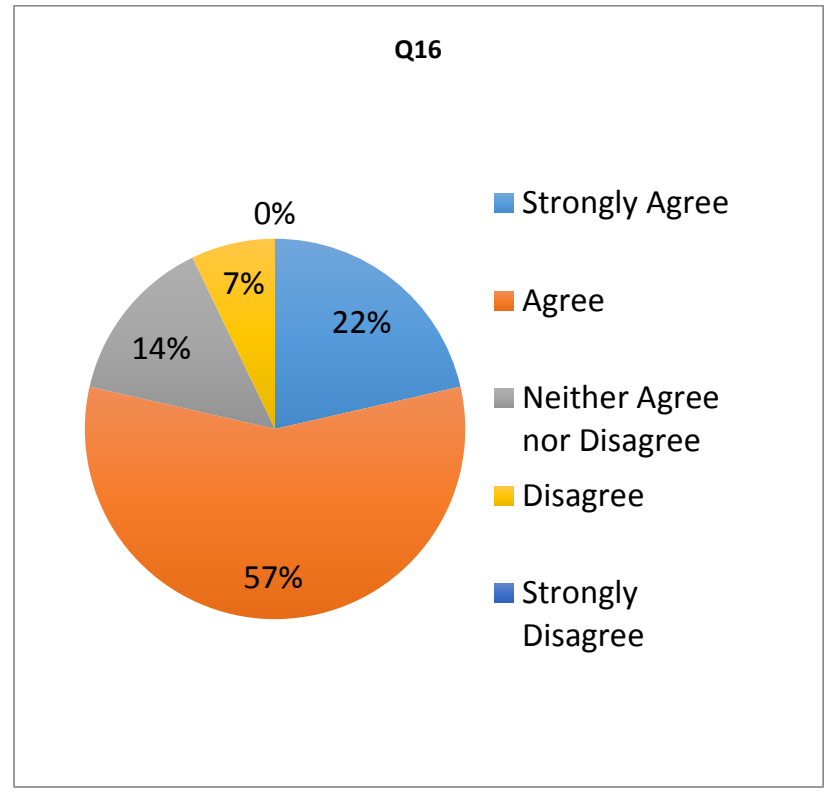

